\title{
INOVAÇÕES TECNOLÓGICAS NA EDUCAÇÃO PROFISSIONAL PARA O EMPREENDEDORISMO E EMPREGABILIDADE
}

\author{
Iolanda Bueno de Camargo Cortelazzo ${ }^{1}$
}

\section{RESUMO}

O artigo discute algumas competências fundamentais para jovens e adultos egressos do Ensino Médio ou que abandonaram o Ensino Superior poderem se inserir no mercado de trabalho. A empregabilidade, o empreendedorismo e a inovação tecnológica são três dessas competências que, em geral, são desconhecidas dos gestores e docentes da Educação Básica, em especial dos anos finais do Ensino Fundamental e Ensino Médio, bem como dos docentes do Ensino Superior no Brasil. Essas competências são apresentadas a partir de uma revisão de literatura estrangeira, acompanhadas de algumas reflexões e recomendações aos docentes da Educação Básica e da graduação, formadora de profissionais, em geral e de professores, em especial, bem como para elaboradores de políticas educacionais.

Palavras-chave: Inovação tecnológica; Educação profissional; Empreendedorismo; Empregabilidade.

\section{TECHNOLOGICAL INNOVATION IN PROFESSIONAL EDUCATION FOR ENTREPRENEURSHIP AND EMPLOYABILITY}

\begin{abstract}
This article discusses some fundamental competences for young people and adults who had finished high school or undergraduate students, who have quit, could enter the job market. Employability, entrepreneurship and technological innovation are three of those competences which have been commonly unknown by school managers and teachers of Basic Education in Brazil. Those competences are introduced from a review of foreign research, followed by some comments and recommendation teachers who work with Basic Education and undergraduate, as well as teachers, professional trainers in general, and specially teacher trainer, as well as to teacher who develop Education Policy.
\end{abstract}

Keywords: Technological innovation; Professional education; Entrepreneurship; Employability.

\section{INNOVACIONES TECNOLÓGICAS EN LA EDUCACIÓN PROFESIONAL PARA EL ESPÍRITU EMPRESARIAL Y EMPLEABILIDAD}

\section{RESUMEN}

Este artículo discute algunas competencias fundamentales para que jóvenes y adultos salidos de la Escuela Secundaria o que dejaron la Enseñanza Superior puedan se insertar en el mercado de trabajo. La empleabilidad, el espíritu empresarial y la innovación tecnológica son tres de esas competencias que, en general, son desconocidas de gestores y docentes de la Educación Básica, en especial de los años finales de la Enseñanza Básica y Escuela Media, como de los docentes de la Enseñanza Superior en Brasil. Esas competencias son presentadas desde una revisión de literatura extranjera, acompañada de algunas reflexiones y recomendaciones a los docentes de la Enseñanza Básica y Superior, formadora

\footnotetext{
${ }^{1}$ Professora Adjunto e Coordenadora de Tecnologia na Educação da UTFPR Universidade Tecnológica Federal do Paraná. Pesquisadora de EAD, tecnologiaas na educação, Recursos Educacionais digitais, emreendedorismo, empregabilidde e inovação. E-mail: <icortelazzo@utfpr.edu.br>
} 
de profesionales en general, y de profesores, en especial, como los que elaboran políticas educacionales.

Palabras-clave: Innovación tecnológica; Educación profesional; Espíritu empresarial; Empleabilidad.

\section{Introdução}

As tecnologias digitais aplicadas à educação no sentido tradicional, às novas formas de educação online ou à educação aberta podem promover a aprendizagem para além da teoria, preparando os estudantes para a inserção no trabalho, pois permitem projetos de aplicação da teoria na prática a partir de interesses dos estudantes e professores, e das necessidades específicas da sociedade. Esse cenário é marcado por uma ecologia do conhecimento, que permite a utilização de arquiteturas abertas em projetos de software, em que surgem novos espaços de leitura e novas estruturas organizacionais. Essa ecologia propicia, ao professor, o acompanhamento, mais de perto, da aprendizagem dos estudantes e o processo de apropriação de competências que lhes serão necessários ao saírem, seja do Ensino Médio, seja da graduação.

O cenário atual, possibilitado pelas tecnologias digitais, pode transformar os estudantes, que têm sido consumidores de conhecimento, em produtores, e de consumidores de tecnologia, também em seus produtores.

Com a Web 2.0 e o contexto das tecnologias digitais, a educação aberta apresenta nova configuração, no sentido lato da palavra aberta, cursos, oficinas, instruções, artigos com reflexão, e propostas de alternativas em várias áreas estão disponibilizadas ao acesso público. Muitas dessas oportunidades de estudo, aprofundamento e capacitação são disponibilizadas de forma aberta e gratuita, e permitem aos estudantes ou egressos do Ensino Médio aprofundar conhecimentos e habilidades se, ao longo de sua escolaridade, as competências para aprender a aprender foram desenvolvidas.

Nesse contexto, este artigo é resultado de reflexões sobre a própria prática a partir da análise de dados registrados durante os cinco últimos anos de atuação da autora como docente e orientadora de projetos e monografias nos cursos de formação continuada de professores no PDE (SEEDPR), nos cursos técnicos subsequentes e-Tec, em cursos de licenciatura da UTFPR, em cursos de especialização em Gestão e Docência na EAD (parceria da UFSC, UTFPR, CEFETMG e IFSC) e de especialização em Tecnologia, Comunicação e Técnicas 
de Ensino (UAB/UTFPR). O projeto de pesquisa, Tecnologias Digitais na Educação: novas mediações na educação superior, consolidou algumas percepções conseguidas na prática profissional docente nos diversos níveis (Educação básica, Graduação, pós-graduação) e nas diferentes modalidades (presencial e a distância) de atuação da pesquisadora, e indicou outras em relação ao uso das tecnologias digitais e desenvolvimento de competências, como inovação, empregabilidade e empreendedorismo no Ensino Médio e na Graduação.

Constatou-se que há uma grande lacuna entre as competências efetivamente obtidas na Educação Básica e o atendimento dos requisitos mais simples de empregabilidade nos diferentes níveis e setores da sociedade. No cotidiano, observa-se a rotatividade de empregados em boa parte dos estabelecimentos comerciais, ou entre aqueles que atendem os serviços domésticos. No serviço público, cujos concursos demandam questões objetivas, muitos candidatos selecionados não têm as competências básicas para a convivência e interação social proativa, comprometida e colaborativa. Nas agências de emprego, nos departamentos de recursos humanos, constata-se o mesmo tipo de insatisfação em relação aos requisitos solicitados pelos empregadores e as competências demonstradas pelos candidatos. As grandes empresas optam por realizar capacitação e formação interna; as pequenas empresas submetem-se à troca constante de empregados; e o serviço público sujeita-se ao possível, pois a estabilidade no emprego dificulta o desejável e necessário.

A partir desta reflexão, este artigo apresenta algumas considerações sobre educação geral e educação profissional, e busca encaminhar algumas questões em relação às competências já referidas, como inovação tecnológica, empregabilidade e empreendedorismo, que podem ser tratadas na Educação Básica como possibilidade de solução para estudantes egressos do Ensino Fundamental e do Ensino Médio que não desejam ou não têm condições de cursar o nível superior, para os que abandonaram o curso superior sem concluí-lo e para aqueles que buscam uma atividade laboral que não exija formação de nível superior. Finaliza-se o artigo com algumas considerações e sugestões sobre a temática.

\section{Educação geral e educação profissional}

A base da competência é o conhecimento. Assim, professores, para poderem ser orientadores competentes da aprendizagem de seus alunos, precisam inicialmente considera- 
los estudantes ${ }^{2}$ e tratá-los como tal. Outras duas características da competência referem-se às habilidades (sociais, operacionais, metodológicas) e atitudes que possam mobilizar os conhecimentos para se alcançarem os objetivos definidos e os resultados esperados.

Na década de 2000 e na primeira metade da década de 2010, intensificou-se a política de educação para todos, seguindo as recomendações das políticas educacionais internacionais; porém, com característica marcadamente populista e paternalista. Sob o tema de inclusão social, esvaziaram-se os requisitos de competência escolar, tanto no ingresso quanto na aprovação dos alunos; superficializou-se a construção do conhecimento; restringiuse o desenvolvimento de habilidades, suprimiu-se o desenvolvimento de atitudes de respeito, disciplina, organização, pontualidade, assiduidade, entre outros. Passou-se a defender a igualdade de todos, sem a respectiva equidade: isto é, todos têm direito, ainda que não sejam competentes. Passou-se a definir meritocracia e condenar a prática de exigir conhecimento, habilidades e atitudes apropriadas para a aprovação escolar. Ignorou-se que a inclusão e a promoção escolar criavam a exclusão social e a exclusão profissional, embora tivessem aumentado os índices estatísticos educacionais de ingresso no Ensino Médio e no Ensino Superior no Brasil, nos levantamentos mundiais.

Esse cenário de desvalorização da educação teve e continua tendo, como consequência, uma baixa de qualidade de ensino, pois, com professores que têm menos conhecimento, habilidades e deixaram de aprender atitudes próprias da docência, a pouca aprendizagem dos alunos é cada vez maior. Mais grave ainda é que os alunos do Ensino Fundamental não se transformaram em estudantes no Ensino Médio. Ainda mais preocupante é que muitos indivíduos que não se constituíram como estudantes no Ensino Médio também não se constituíram como estudantes no Ensino Superior e, portanto, não se desenvolveram para serem profissionais competentes, criativos, inovadores, proativos, solucionadores de problemas, comprometidos, responsáveis, nem se transformaram em cidadãos críticos propositivos. Neste caso em particular, constatamos a formação de pessoas críticas acomodadas, massa doutrinada e manipulável, reprodutora de uma ideologia que desvaloriza e desconfigura a identidade brasileira, seja na sua história, seja na sua cultura.

Quando esses profissionais são professores do Ensino Básico, do Ensino Profissional e do Ensino Superior, os resultados de sua ação são desastrosos. De um lado, a

\footnotetext{
${ }^{2}$ Estudante: aquele que estuda.
} 
falta de domínio do conhecimento de sua área de ensino, de didática e de aplicações tecnológicas afasta, da aprendizagem, crianças, adolescentes e jovens, tornando-os apáticos ou indisciplinados, visto que não reconhecem, nos professores, os líderes que poderiam motivá-los, orientá-los e estimulá-los no caminho da construção do conhecimento pessoal, social ou profissional. De outro lado, essa falta de conhecimento e a reprodução de uma ideologia imposta, não construída conscientemente, levam esses profissionais a reproduzirem a mesma prática destrutiva do sistema, sem a proposição de soluções alternativas para os problemas que criticam. São professores, mas não profissionais da educação, não são professores na verdadeira acepção da palavra.

Alguns estudos - como o de Pochmann (2004) - indicam que, na década de 1990/2000, os índices de escolaridade de jovens pobres cresceram, mas as taxas de desemprego nessa faixa etária também cresceram, indicando um preconceito em relação aos jovens mais ricos que apresentavam índices de desemprego menores. Porém, esses trabalhos não questionam o nível de qualidade da escolaridade desses jovens desempregados. Não seria a questão de se pesquisar exatamente sobre a política educacional de inclusão quantitativa, não qualitativa? Esta é apenas uma provocação para futuras pesquisas.

No entanto, ainda há muitos profissionais que se desenvolveram como gestores educacionais e professores conscientes de sua função na sociedade, que foram estudantes no Ensino Médio e no Ensino Superior, e que continuam a buscar o aprofundamento do conhecimento específico, didático, metodológico e tecnológico. Muitos são os que desenvolvem as habilidades e atitudes necessárias para uma docência responsável, que propicie aprendizagem significativa agregadora de valores nos desempenhos pessoais, sociais e profissionais de seus estudantes. Profissionais que se desenvolveram como questionadores e, indo além do que seus mestres propunham, sedimentaram ideias trazidas por eles, ou que, através de leituras e estudos aprofundados sobre os contrapontos àquelas ideias, sedimentaram novas ideias e novas tendências, aproveitando as diferentes perspectivas permitidas por seus mestres.

Nesse contexto, também se busca entender mais sobre a Educação Profissional e a conceituação de algumas competências, nem sempre estudadas na formação inicial de docentes e gestores, bem como algumas indicações de possibilidades a serem desenvolvidas, em particular no Ensino Médio, para que seus egressos possam ter autonomia para a 
empregabilidade ou para o empreendedorismo em uma sociedade mediada pelas tecnologias digitais, em um contexto desafiador, de crise, mas de amplas potencialidades.

A tradição ibérica que predomina na formação cultural brasileira tem como marca dominante uma educação propedêutica para as elites, encaminhando-as, inclusive, para o ensino superior, reservando para as famílias mais pobres o encaminhamento de seus filhos para o trabalho manual e para o desenvolvimento de técnicas.

Conforme Soares indica, em seu texto sobre fazeres e saberes da educação profissional, que a escolarização era organizada através de escolas "técnicas", escolas "de artes e ofícios", escolas "industriais", escolas "polivalentes", escolas "do trabalho", escolas "comerciais" e escolas "politécnicas" (SOARES, 2008, p. 3), desvinculada de uma educação humanista mais voltada para as elites. Indica, ainda, o autor, citando Oliveira, que a escola profissionalizante não pode ser apartada da educação geral, mas integrada a ela com densidade crítica e reflexiva, sendo capaz de levar o "trabalhador a ser cidadão de seu país e do mundo" (OLIVEIRA, 2007, p. 13 apud SOARES, 2008, p. 3).

Também autores como Gariglio e Burnier (2012) indicam a falta de reconhecimento dos professores de Educação Profissional, referindo-se ao Decreto 2208/97, que "permitiu que a figura do professor fosse substituída pelo instrutor ou monitor", reduzindo, a responsabilidade docente ao treinamento ou à capacitação, não reconhecendo "a complexidade do ato educativo" (GARIGLIO; BURNIER, 2012, p. 213). Chamam a atenção para a falta de interesse na formação crítica dos profissionais que são docentes na educação profissional, pois esses poderão influenciar, com o foco na autonomia dos estudantes e preparação crítica, "levantar questionamentos na relação ensino x aprendizado sobre os usos, objetivos e implicações da tecnologia" ou "sobre a relação capital x trabalho" (GARIGLIO; BURNIER, 2012, p. 213).

As políticas educacionais ao longo das décadas de 1990, 2000 e 2010 não têm valorizado a educação profissional; ao contrário, reorientam o fluxo dos jovens das camadas mais pobres para a educação superior, em uma visão equivocada de inclusão social, reforçando a subvalorização da educação técnica e profissional de nível médio, sistemas de cota, Pró-Uni e outras medidas de facilitação de acesso ao Ensino Superior, pontuais, mas não estruturais.

Toma-se, como referência, um movimento coordenado pela Secretaria Estadual de Educação do Rio Grande do Sul que, em novembro de 2011, apresentou a Proposta 
Pedagógica para o Ensino Médio Politécnico e Educação Profissional Integrada ao Ensino Médio - 2011-2014, na qual propunha o Ensino Médio como etapa final da Educação Básica, desenhado a partir da integração do Ensino Médio com o mundo do trabalho. Em outras palavras,

[...] uma mudança estrutural que coloque o Ensino Médio para além da mera continuidade do Ensino Fundamental, instituindo-o efetivamente como etapa final da educação básica. Um Ensino Médio que contemple a qualificação, a articulação com o mundo do trabalho e práticas produtivas, com responsabilidade e sustentabilidade e com qualidade cidadã (SEEDRS, 2011, p. 4) (grifos nossos).

Um dos princípios importantes dessa proposta é que o Ensino Médio tenha uma identidade consistente que permita "reverter o alto índice de evasão e reprovação com qualidade social" e que esse Ensino Médio "oportunize e se empenhe na construção de projetos de vida pessoais e coletivos que garantam inserção social e produtiva com cidadania" (SEEDRS, 2011, p. 4).

Para isso, é fundamental que tanto a formação inicial como a formação continuada dos professores tenham, em sua estrutura curricular, o foco de educação profissional, isto é, desenvolvimento de um aprendiz da profissão de professor em um professor profissional em constante processo de aprendizagem, com foco na aprendizagem dos seus estudantes.

Dessa forma, não é possível que se ignorem as competências necessárias para uma inserção dos jovens no trabalho. É preciso, antes, orientá-los a saberem o que o mundo lhes oferece, o que eles desejam fazer, a se prepararem para se tornarem o que desejam ser, a aprenderem para serem competentes em qualquer ocupação que escolham e, se forem competentes, poderão reivindicar seus direitos.

Assim, para que todos os professores na Educação Básica possam ter a competência de preparar seus estudantes de modo que possam se inserir como cidadãos e indivíduos produtivos na economia de seu país, é fundamental que conheçam os conceitos de autonomia, inovação, empregabilidade e empreendedorismo. Conforme Rey escreve, "conhecer um conceito é conhecer seu poder no sentido de que o poder é uma ferramenta conceitual que pode resolver um número considerável de problemas" (REY, 1998, p. 204 apud MARTINET, 2001, p. 49). Isto é, ao se aprofundar no conhecimento desses conceitos que se propõem aqui, os professores poderão orientar a aprendizagem de seus estudantes, 
auxiliando-os a desenvolverem essas competências propostas para uma possível terminalidade de seus estudos no Ensino Médio.

Não há a intenção de fazer uma discussão do conceito autonomia. Por essa razão opta-se por apresentar uma definição que foi proposta em um debate sobre o conceito de autonomia e que se adéqua a esta perspectiva aqui apresentada:

Autonomia é ter o poder de decidir com responsabilidade sobre ações do seu cotidiano. Porém ter autonomia não significa ser isolado, ser soberano. Pelo contrário, ter autonomia é ser um indivíduo participativo, que sabe trabalhar no coletivo, visando construir sua própria identidade, que tenha ideias próprias e aceite as dos outros, proponha alternativas de solução para obstáculos e dificuldades encontradas no dia a dia, articule novos conhecimentos e conteúdos de ensino com experiências e vivências dos colegas e outros. Dessa forma, autonomia admite a diferença e, por isso, supõe a parceria. Só a igualdade na diferença e a parceria são capazes de criar o novo. Por isso, indivíduo autônomo não significa que está isolado, mas em constante intercâmbio com as demais pessoas (MG) (grifos nossos).

Nesta perspectiva, a autonomia se amplia se o indivíduo souber aproveitar as possibilidades de conectividade permitidas pelas tecnologias digitais. Através delas, cada um pode, a qualquer momento e em qualquer lugar, buscar seu autodesenvolvimento, redefinir um propósito, acessar diferentes fontes de conhecimento, criar ou participar de comunidades de aprendizagem, de práticas ou de pesquisa, influenciar outros indivíduos e impactar na melhoria de sua comunidade. Esta competência é o alicerce para outras competências que precisam ser desenvolvidas transversalmente no currículo da Educação.

\section{Empregabilidade, Empreendedorismo e Inovações tecnológicas}

Três das competências que precisam ser compreendidas no contexto das últimas três décadas de grandes transformações globais, inclusive tecnológicas, que impactaram o trabalho (seja no âmbito empresarial, seja no âmbito individual) e que são essenciais para a inserção de jovens e adultos no mercado de trabalho são empregabilidade, empreendedorismo e inovação tecnológica. Elas são estudadas aqui a partir de uma revisão bibliográfica e de experiências estrangeira.

\section{Empregabilidade}


Esta competência é analisada a partir de duas perspectivas, a do empregador e a do empregado. A empregabilidade é entendida, pela empresa, como um conjunto de competências que o indivíduo deve ter. À medida que as transformações econômicas, sociais, culturais e tecnológicas acontecem, essas competências de empregabilidade precisam ser consideradas para a mudança de fundamentos da formação profissional (KRAUS, 2007). Aponta a necessidade de colaboração entre os setores educacionais e o mercado de trabalho no sentido de ofertar, aos empregados, teoria (educação) e aplicação (prática no setor privado) (ABRAHAM, 2016). Na mesma direção, Loufrani-Fedida e Saint-Germes (2013) enfatizam que as empresas precisam uma profissionalização da valorização de suas práticas de RH.

Na perspectiva do empregado, Kraus refere-se tanto à necessidade quanto à disponibilidade de compreender "as diferentes fases do seu percurso profissional" para se "adaptar as competências de sua força de trabalho às exigências do mercado". Chama, ainda, a atenção para a necessidade de orientação e formação profissional (KRAUS, 2007, p. 4).

Para quem desejar aprofundar-se no tema, Loufrani-Fedida e Saint-Germes reportam as transformações que a noção de empregabilidade tem a partir das questões de emprego e de formação profissional desde a década de 1990, apresentadas tanto no âmbito privado quanto público. Referem-se, também, aos direitos adquiridos pelos trabalhadores em contraponto com um mercado de trabalho cada vez "mais volátil que impõe uma flexibilização bem maior" (LOUFRANI-FEDIDA; SAINT-GERMES, 2013, p. 20). Eles até veem a empregabilidade como condição necessária ao desenvolvimento "de uma vantagem competitiva duradoura para a empresa e de sucesso de carreira para o indivíduo" (LOUFRANIFEDIDA; SAINT-GERMES, 2013, p. 20).

De acordo com Saint-Germes (2004), empregabilidade "é a capacidade de ser empregado"; e, embora esse termo seja usado nas políticas de emprego e inserção profissional, a sua integração à política social das empresas continua limitada pelas situações de urgência, que se apresentam cotidianamente. Esse conceito tem uma dimensão sistêmica e mista, pois integra ao mesmo tempo os níveis individuais, organizacionais e do mercado de trabalho e de representações (SAINT-GERMES, 2004, p. 1888). O autor enfatiza, ainda, as condições de gestão de recursos humanos que garantem ao indivíduo ter um emprego: "A empregabilidade é um conjunto de competências e de condições de gestão de recursos humanos necessários e suficientes para permitir a um assalariado de encontrar a qualquer 
momento um emprego dentro ou fora de uma empresa, em prazos e condições razoáveis". (SAINT-GERMES, 2004, p. 1889).

Ao definir a empregabilidade como interativa por articular as capacidades individuais dinâmicas ao ambiente com o qual ela interage, Saint-Germes a considera a capacidade que o indivíduo tem de conseguir um emprego satisfatório, tendo em conta as interações de suas competências com os requisitos do mercado de trabalho. $\mathrm{O}$ autor ressalta o caráter sistêmico da empregabilidade, que inclui referências ao indivíduo, à organização e ao mercado de trabalho. "Essa natureza sistêmica e a evolução da noção de emprego caracterizam uma empregabilidade de natureza dinâmica, um verdadeiro processo perpétuo e interativo de adaptação ao mercado de trabalho" (SAINT-GERMES, 2004, p. 1890).

A empregabilidade incorpora competências profissionais, sociais e pessoais, além da disponibilidade individual; flexibilidade, mobilidade e pensamento empreendedor podem ser características da empregabilidade; e cada vez mais, a discussão se faz em relação à empregabilidade individual (KRAUS, 2007).

Nessa perspectiva, Abraham indica que a empregabilidade é um elemento intangível da identidade de um indivíduo (ABRAHAM, 2016, p. 90); sendo assim, essa competência precisa ser trabalhada desde a Educação Básica, de modo que os egressos tenham consciência dela e possam explicitá-la ao se candidatarem a um emprego.

Ao pensar que, na atualidade, em todos os níveis sociais, os jovens têm acesso à Web via celulares, tablets, desktops, em lan houses ou em bibliotecas públicas, faz-se necessária uma educação digital que os transformem em usuários críticos dessas tecnologias digitais, mais do que consumidores, criadores e adaptadores do aprendido para novos contextos e novos cenários.

É importante que os professores, tanto na educação básica como no ensino superior compreendam que, em tempos de inovações tecnológica digitais, precisam valorizar o metaconhecimento (conhecimento sobre o conhecimento) e, como afirma Schettino, "agora que tantas informações são livremente acessíveis, nas atividades de formação se requer uma construção conjunta de sentido e de significado através de uma didática de matriz heurística" (SCHETTINO, 2013, p. 60). Isto significa que não basta o acesso às informações em diferentes linguagens disponíveis na Web: é fundamental que se tenha a consciência e ferramentas cognitivas para fazer a separação a partir de critérios de fidedignidade, veracidade, profundidade, continuidade, entre outros. 
Na Austrália, o Departamento de Educação, Ciência e Treinamento desenvolveu um guia de orientação para o desenvolvimento de habilidades de empregabilidade para orientar a ação educativa. Esse guia tem como objetivo um sistema capaz de desenvolver, na educação profissional, um conjunto de habilidades, atitudes e comportamentos necessários para a eficaz e efetiva atuação no ambiente de trabalho, com ênfase nas habilidades de empregabilidade. Essa é uma demanda constatada nas empresas e, portanto, o sistema educacional precisa fazer com que os egressos que serão candidatos aos empregos disponíveis tenham essas habilidades e saibam demonstrá-las (NCVR, 2006, p. 5).

Diante do número expressivo de pessoas desempregadas na Europa, a Comissão Europeia tem políticas específicas de aprendizagem adulta para qualificação e nova capacitação para novas ocupações. A Comissão Europeia desenvolveu alguns sistemas de educação adulta que se caracterizam por "flexibilidade, alta qualidade, ensino de excelência e total envolvimento com autoridades locais, empregadores, parceiros sociais, sociedade civil e organizações culturais" (EURPEAN COMISSION, s/d).

Em 2011, a Comissão Europeia criou a Agenda Europeia Renovada para a Aprendizagem Adulta, estabelecendo as seguintes prioridades para o período 2015-2020: governança (garantia de coerência no atendimento das necessidades sociais); oferta e participação (efetiva provisão de aprendizagem adulta de alta qualidade e retomada de estratégias de orientação e motivação de grupos mais necessitados); flexibilidade e acesso (uso efetivo das TIC e dos locais de trabalho para qualificação para o trabalho); e qualidade (pesquisa de necessidades na área de educação continuada e educação continuada de alta qualidade dos educadores de educação de adultos). Para dar forma e efetividade a essas prioridades, um grupo de trabalho preparou, nos períodos de $2014 / 2015$, um guia orientando a busca de maior efetividade nas políticas e oferta de aprendizagem adulta; redação de um relatório orientando para melhor uso das tecnologias digitais na aprendizagem adulta; além de orientação para a melhoria das habilidades de letramento, numerácia e digitais de adultos (EUROPEAN COMISSION, 2015, p. 1-297); A Comissão Europeia tem uma plataforma eletrônica para aprendizagem adulta - EPALE, "uma comunidade aberta multilíngue para professores, instrutores, pesquisadores acadêmicos, legisladores e qualquer pessoa com um papel profissional na educação adulta na Europa" (EUROPEN COMISSION - EPALE, 2014). Nessa plataforma existe uma biblioteca de recursos que podem ser utilizados por profissionais da educação que trabalham com a aprendizagem de adultos. 
Em 2012, na Proposta para a regulamentação do Parlamento Europeu e do Conselho estabelecendo o Programa da União para Educação, Treinamento, Juventude e Esporte, Erasmus para todos, a Comissão Europeia apresentou algumas recomendações "para três tipos de ação: oportunidades de aprendizagem individuais; cooperação entre diferentes tipos de instituições; e apoio para reformas nos Estados membros para modernizar os sistemas de educação e treinamento, e promover inovação, empreendedorismo e empregabilidade" (EUR, 2012, p. 155).

Essas duas situações são apresentadas como ponto de partida para pensar que já está atrasado, no Brasil, um movimento equivalente para dar possibilidades efetivas a milhões de pessoas que se encontram desempregadas, não só pelas condições conjunturais de crise política e econômica, também por razões estruturais da educação profissional no Brasil.

Como caracterização das competências de empregabilidade, no que se refere às habilidades e atitudes, destacam-se cinco grupos: Comunicação e habilidades básicas (oralidade, leitura e compreensão, redação com foco na audiência, persuasão, empatia); habilidades de ordem superior (solução de problemas, estratégias e habilidades de aprendizagem, pensamento inovador, crítico propositivo, tomada de decisões); habilidades de organização e planejamento (identificação e oportunidades; administração do tempo; predição, investigação sistematizada); habilidades operacionais (domínio de ferramentas digitais básicas de comunicação e processamento de dados); e atitudes e características afetivas (atitudes em relação ao trabalho, à eficiência, ao estabelecimento de redes e conexões, às regras de colaboração, à autoconfiança e autoestima, adaptabilidade, motivação, autoavaliação, honestidade e integridade, habilidade para trabalhar sem supervisão) (adaptado de COTTON, 1999).

\section{Empreendedorismo}

Esta é uma competência pouco valorizada na educação profissional no Brasil. Pouca literatura sobre o tema levou a autora a buscar em outras línguas e optar por exemplos de como essa competência tem sido trabalhada fora do Brasil, sem pretender esgotar o tema.

De acordo com a NFTE, em junho de 2016, setenta e três milhões de jovens estão desempregados em todo o mundo, e a previsão para os próximos vinte anos é de que aproximadamente seiscentos milhões de jovens estarão procurando por empregos (NFTE, 
2016). Urge preocupar-se com o desenvolvimento de competências que permitam aos jovens a se diferenciarem ou a se lançarem como empreendedores.

Entre as fontes de pesquisa, destaca-se um movimento americano junto às comunidades mais carentes, realizado pelo Network For Teaching Entrepreneurship - NFTE (Rede Pelo Ensino do Empreendedorismo), cuja missão "é prover programas que inspirem os jovens de comunidades de baixa renda permanecerem na escola, reconhecer oportunidades de negócios e planejar futuro". Essa Rede começou com o objetivo de "prevenir evasão escolar e melhorar o desempenho acadêmico dos estudantes que estavam em situação de risco, de abandono da escola ou em repetência" (NFTE, 2016). Essa Rede descobriu que pode levar esses jovens a entender que o que eles aprendem na escola tem a ver com o mundo real, as "street smarts"3 (habilidades de rua) transformam-se em habilidades acadêmicas, os jovens percebem que as disciplinas escolares podem ser relevantes em suas vidas, e eles podem desenvolver sua capacidade empreendedora (inovação, pensamento crítico e correr riscos). Dessa forma, os professores estão municiando-os com habilidades e atitudes para vencer a adversidade e preparar-se para o futuro (NFTE) ${ }^{4}$. As atividades docentes e de mentores levamnos a aprofundar seus conhecimentos no currículo da escola secundária e criar pequenos negócios, nos quais eles precisam demonstrar a capacidade empreendedora.

Os pesquisadores do NFTE identificaram oito fatores críticos para a capacidade empreendedora: reconhecimento de oportunidade, conforto em situação de risco, criatividade e inovação; orientação do futuro; flexibilidade e adaptabilidade; iniciativa e autoconfiança, pensamento crítico e solução de problemas; e comunicação e colaboração.

Dentre as atividades trabalhadas pelos programas do NFTE voltados para o desenvolvimento da capacidade empreendedora, destaca-se uma em parceria com a Microsoft, em que os estudantes foram desafiados a produzir um programa para celulares, Entre eles, três selecionados desenvolveram três produtos voltados para o uso educacional dos próprios estudantes 5 .

\footnotetext{
${ }^{3}$ Street smarts: a habilidade de gerenciar ou se sair bem, em situações difíceis ou perigosas especialmente nas grandes cidades; academic smarts: habilidade de serem bem-sucedidos nas atividades escolares.

${ }^{4}$ Cerca de 700.000 jovens de comunidades de baixa renda em programa nos Estados Unidos e em outras regiões do mundo, já foram atingidos.

${ }^{5}$ Programas que podem ser conhecidos no site Word Series Innovation.

$<$ http://innovation.nfte.com/challenges/microsoft-app>
} 
Essa Rede tem um centro de orientação para professores, o NFTE Connect, para que eles possam incorporar a educação para o empreendedorismo em sua prática pedagógica de modo a ajudarem seus jovens estudantes, ensinando-lhes habilidades não cognitivas que ajudam a colocar os objetivos educacionais em um contexto de sucesso no mundo real (NFTE, 2016b).

Outra iniciativa que alcança uma população ainda maior é a realizada pela Comissão Europeia, no âmbito de Educação e Treinamento que, além das ações de Educação para a empregabilidade, tem um programa de desenvolvimento de potencialidades, Empreendedorismo na Educação. Nesse Programa, a premissa é que as pessoas precisam de uma capacidade empreendedora, habilidades e conhecimento para poderem empreender. Assim, várias ações são desenvolvidas por indivíduos, educadores, instituições de ensino e formuladores de políticas (EUROPEAN COMISSION, 2014).

\section{Inovação tecnológica}

As inovações tecnológicas, neste artigo, restringem-se às inovações tecnológicas digitais e implicam outras competências na Educação profissional

Entende-se, aqui, inovação tecnológica como uma atividade que objetiva introduzir novos produtos, novos serviços, novos métodos de produção, de distribuição e de uso dessas mesmas tecnologias. É fundamental que apresentem resultados que satisfaçam os usuários na consecução dos seus objetivos de uso com um diferencial em relação às tecnologias existentes. A inovação tecnológica pode ser radical (substituição integral que impacta fortemente diferentes setores) ou incremental (adaptações, reusos, reorganização, fusão, que incorpora novos produtos, metodologias e processos com menor impacto). A inovação tecnológica é mais do que um fato científico-técnico; caracteriza-se como um processo social dinâmico acompanhado de outras ações relativas às suas características estéticas, de gestão, de marketing, de viabilização de produção e distribuição (SIRILLI, 2008, $5 / 20)$

Na mesma direção, Schettino refere-se à existência de "uma nova forma antropológica e uma forma de mundo nunca vista antes quase totalmente coincidente com a web que se configura como um espaço mais ou menos identificável" (SCHETTINO, 2015, p. 57). Às conotações precisas tradicionais do individualismo, silêncio, concentração e 
sedimentação, opõem-se novas conotações como a velocidade, o compartilhamento, a inteligência coletiva (SCHETTINO, 2015, p. 57). Essas conotações incorporam-se aos poucos, podem causar resistência, e precisam ser consideradas, em especial na formação profissional dos indivíduos.

Nas três últimas décadas, as transformações tecnológicas quebraram barreiras de espaço e tempo, modificando os diferentes segmentos da sociedade, suas relações, bem como tipos e modos de comunicação, levando as pessoas a utilizarem computadores, tablets e celulares para fazerem, de forma diferente, o que faziam sem esses dispositivos, mas também tendo novas oportunidades que não possuíam. As tecnologias digitais que amplificam essas possibilidades multiplicam as interações humanas nas telas digitais, em outro tempo possível tecnologicamente, como "aquele do intercâmbio e da sincronização das atividades de pensamento, de conhecimento e de experiência" (IERVOLINO, 2015, p. 18).

Assim, chama-se a atenção dos educadores para a necessidade da reorganização dos saberes que, nesta sociedade do conhecimento e complexa, se tornam fluidos e demandam, também, o desenvolvimento de competências autênticas.

Os educadores, gestores e professores precisam se atualizar e tornarem-se conscientes das potencialidades e riscos decorrentes do uso das tecnologias na educação, com reflexão permanente sobre as funções da escola em relação à preparação dos estudantes para uma efetiva cidadania digital ativa e responsável. Bevilacqua reforça que é necessário "pensar as tecnologias como oportunidades válidas para mobilizar toda uma gama de capacidades humanas [...]" e construir sentido com o próprio "agir pensando em interação social" (BEVILACQUA, 2011, 17/25). A autora lembra, ainda, que as tecnologias digitais e telemáticas, bem como as tecnologias sociais emergentes precisam ser trabalhadas na educação como "instrumentos capazes de romper as barreiras tecnológicas e econômicas, a exclusão digital, causadora da exclusão de conhecimento para a efetiva globalização do saber" (BEVILACQUA, $2011,18 / 25)$.

Abraham apresenta reflexões e recomendações relativas às interações entre seres humanos e tecnologia e às interações entre seres humanos em um movimento de se pôr fim às barreiras que mantêm o isolamento de grupos de pessoas de uma instituição e de se promoverem interações, compartilhamentos no mundo do trabalho (ABRAHAM, 2016, p. 46). Coloca-se, então, o problema de como selecionar recursos nas mais diferentes linguagens, nas mais diversas visões, como trabalhar com eles, organizá-los e compartilhá-los. Esta 
configuração que se constrói desde a última década do século XX requer novas competências: investigativa (buscar a informação, sabendo navegar no espaço virtual com diferentes buscadores e suas diferentes funcionalidades); organizativa (selecionar, classificar, estruturar, e sintetizar as informações coletadas); e heurística ("avaliar os recursos em rede de acordo com sua pertinência, veracidade, significância, eficácia didática, possibilidades e oportunidades de uso, qualidade dos conteúdos") (GUGLIELMAN, 2013, p. 40).

Nesse cenário, Ferrari e Tróia (2015) alertam para a necessidade de uma reflexão sobre a inclusão digital e a possibilidade de todos usufruírem das vantagens das tecnologias digitais que pressupõem o desenvolvimento de competências digitais. Mais do que direito de acesso à tecnologia, é preciso consciência e competências digitais para usar a tecnologia disponível "para agir neste domínio da cidadania (no qual o analógico e o digital se integram progressivamente em todos os âmbitos" (FERRARI; TROIA, 2015, p. 2).

\section{Considerações Finais}

Ao pesquisar sobre empregabilidade, empreendedorismo e inovação tecnológica a partir do viés da educação profissional, muita é a bibliografia em língua estrangeira que trata sobre essa competência ou movimento, dependendo da perspectiva, voltada para aprendizagem de jovens e de adultos que precisam se empregar ou se empregar novamente, pois estão desempregados, ou desejam mudar de emprego. Incipiente são as pesquisas e a literatura que tratem da educação para a empregabilidade, para o empreendedorismo e para a inovação tecnológica no Brasil.

O interesse da pesquisa em andamento e deste texto foi focar nessas três competências, que os egressos da educação básica (últimas séries do ensino fundamental e ensino médio) ou estudantes que abandonaram a educação superior precisam desenvolver e incorporar como competências transversais à sua formação. Elas são essenciais para que possam se inserir no mercado de trabalho, preferencialmente na sua região. É fundamental que os educadores se compenetrem que não há formação para a cidadania se não houver formação efetiva, eficaz e de qualidade para o trabalho. Gestores escolares, professores, formadores de professores, pesquisadores e formadores de políticas educacionais precisam se comprometer nesse movimento, começando pela formação inicial e continuada dos responsáveis. 


\section{Referências}

ABRAHAM, P. E. Cyberconnecting: The Three Lenses of Diversity. New York: Rutledge, 2016.

AUSTRALIA. Employability Skills in Information and Digital Technology. New South IWales: Board of Studies, 2012. Disponível em:

$<$ https://www.boardofstudies.nsw.edu.au/syllabus hsc/pdf doc/information-and-digitaltechnology-employability-skills.pdf $>$. Acesso em: 01 ago. 2016.

BEVILACQUA, B. Apprendimento significativo mediato della tecnologia. Rivista Scuola laD | Modelli, Politiche R\&T Numero 42011 Disponível em: <http://rivista.scuolaiad.it/n042011/apprendimento-significativo-mediato-dalla-tecnologie>. Acesso em: 14 jun. 2016.

COTTON, K. Research You Can Use To Improve Results. Portland, Or: Northwest Regional Educational Lab., 1999. Close-Up \#15. Disponível em:

<http://educationnorthwest.org/sites/default/files/DevelopingEmployabilitySkills.pdf >. Acesso em: 10 ago. 2016.

EUR. Opinion of the European Economic and Social Committee on the 'Proposal for a regulation of the European Parliament and of the Council establishing "Erasmus for all" The Union Programme for Education, Training, Youth and Sport'. Official Journal of the European Union. Disponível em: < http://eurlex.europa.eu/LexUriServ/LexUriServ.do?uri=OJ:C:2012:181:0154:0159:EN:PDF>. Acesso em 18 ago. 2016.

EU. EPALE. 2014. Disponível em: <https://ec.europa.eu/epale/en/about>. Acesso em: 23 ago. 2016.

EUROPEAN COMISSION. An in-depth analysis of adult learning policies and their effectiveness in Europe. Luxembourg: ICF, 2015, 1-197. Disponível em $<$ https://ec.europa.eu/epale/sites/epale/files/all indepth analysis of adult learning policies and their effectiveness in europe 12.11.2015 pdf.pdf>. Acesso em 23 ago. 2016.

EUROPEAN COMISSION. Entrepreneurship in Education. 2014. Disponível em: <http://ec.europa.eu/education/policy/strategic-framework/entrepreneurship en.htm>. Acesso em: 23 ago. 2016.

EUROPEAN COMISSION. EU policy in the field of adult learning. s/d. Disponível em <http://ec.europa.eu> > European Commission > Education and training > Acesso em: 20 ago. 2016.

FERRARI, A.; TROIA, S. DIGCOMP: Le competenze digitali per la cittadinanza. 2015. Disponível em: <http://dida.orizzontescuola.it/sites/default/files/digcomp Ferrari Troia.pdf >. Acesso em: 18 ago. 2016. 
GARIGLIO, J. A., BURNIER, S. Saberes da docência na educação profissional e tecnológica: um estudo sobre o olhar dos professores. Educação em Revista. Belo Horizonte, v.28 n.01, p. 211-236, mar. 2012. Disponível em:

<http://www.scielo.br/scielo.php?script=sci arttext\&pid=S0102-46982012000100010>. Acesso em: 20 jul. 2016.

GUGLIELMAN, E. Le tecnologie digitali per la didattica tra innovazione e nuove competenze. LIFE DESIGN Research and education Rivista semestrale, 2013.

IERVOLINO, D. E-Learning 3.0 In IERVOLINO, Danilo. e-Learning: tra nuova didattica e innovazione tecnologica. e-book: Giapeto Edittore, 2015.

KRAUS, K. Employabilité: un nouveau concept clé. Dossier : Employabilité, plus qu'une mode Panorama 6. 2007. Disponível em: <http://www.panorama.ch/pdf/2007/pan076f04.pdf>. Acesso em: 20 jul. 2016.

LOUFRANI-FEDIDA, S., SAINT-GERMES E.Compétences individuelles et employabilité : essai de clarification de leur articulation, @GRH 2/2013 ( $\left.n^{\circ} 7\right)$, p. 13-40. Disponível em; <http://www.cairn.info/revue-@grh-2013-2-page-13.htm>. Acesso em: 20 jul. 2016.

MARTINET, M. A.; RAYMOND, D.; GAUTHIER, C. La formation, l' enseignement: Les orientations, Les compètences professionnelles. Quebec: Ministère de I 'Éducation, Gouvernement du Quèbec, 2001, p. 49. Disponível em $<$ http://www.education.gouv.qc.ca/fileadmin/site web/documents/reseau/formation titula risation/formation enseignement orientations EN.pdf>. Acesso em: 15 jul. 2016.

NCVER. Employability skills: from framework to practice: an introductory guide for trainers and assessors. Canberra, Department of Education, Science and Training. Australian Government, 2006. Disponível em: <http://www.voced.edu.au/content/ngv\%3A52958>. Acesso em: 20 jul. 2016.

NFTE. Every Young Person Deserves an Entrepreneurial Mindset, Now. 2016. Disponível em: $<$ https://www.nfte.com/why/blog/every-young-person-deserves-an-entrepreneurialmindset-now>. Acesso em: 18 jul. 2016.

NFTE. Network For Teaching Entrepreneurship, Start it up. 2016bVideo no YouTube Disponível em: <https://www.youtube.com/watch?v=Z26ceJ-OG6o>. Acesso em: 02 ago. 2016.

OLIVEIRA, M. A. M. Políticas públicas para o ensino profissional: o processo de desmantelamento dos CEFETS. São Paulo: Papirus, 2003.

POCHMANN, M. Educação e Trabalho: como desenvolver uma relação virtuosa. Educação e Sociedade, Campinas, vol. 25, n. 87, p. 383-399, maio/ago. 2004. 
SAINT-GERMES, E. L'employabilité, une nouvelle dimension de la GRH ? " 15ème congrès de I'AGRH Montréal, sept. 2004 . 1887-1906. Disponível em <http://www.chairecompetences.uqam.ca/pdf/conferences/Saint-Germes Eve.pdf>. Acesso em 19 jun. 2016.

SEED-RS. SECRETARIA ESTADUAL DE EDUCAÇÂO. Proposta pedagógica para o ensino médio politécnico e educação profissional integrada ao ensino médio: 2011-2014. Porto Alegre: Governo do Estado RS, 2011. Disponível em:

<http://www.educacao.rs.gov.br/dados/ens med proposta.pdf>. Acesso em: 18 jul. 2016.

SCHETTINO, A. Cultura, Communiazione, Cambiamento, Formazione. In IERVOLINO, Danilo. e-Learning: tra nuova didattica e innovazione tecnologica. e-book: Giapeto Edittore, 2015.

SIRILLI, G. Innovazzione tecnologiche. Enciclopedia della Scienza e della Tecnica, 2008 (digital). Disponível em <http://www.treccani.it/enciclopedia/innovazionetecnologica(Enciclopedia-della-Scienza-e-della-Tecnica)/>. Acesso em: 13 ago. 2015.

SOARES, A. S. A educação profissional e o professor: fazeres e saberes necessários. In: I SENEPT, 2008, Belo Horizonte. Anais do I SENEPT. Belo Horizonte: CEFET-MG, 2008. Disponível em: <http://www.senept.cefetmg.br/galerias/Arquivos senept/anais/terca tema3/TerxaTema3 Artig08.pdf>. Acesso em: 20 jul. 2016.

RECEBIDO EM 30 DE SETEMBRO DE 2016.

APROVADO EM 31 DE OUTUBRO DE 2016. 